\title{
Mentes - artes - redes - núvens
}

e.m. de melo e castro

Resumo: A mente inventa o pensamento. A rede difunde a informação. As artes o que farão? A núvem absorve pensamento, arte e informação, transformando-os em qualquer coisa que não sabemos ainda o que é, mas não é de ninguém. A totalidade de todas as informaçôes transmitidas em todas as direçôes, em todas as redes e em todos os momentos, passados, presentes e futuros, por meios electrônicos desmaterializados, constituiu-se numa núvem plural que provávelmente não tem começo nem fim, mas que existe ee "acessável" por qualquer ser humano devidamente equipado ciberneticamente e por isso trnasformado em ciborgue. Assim, o nosso "agora" é complexo e uma estética da complexidade é não só possivel, como necessária para entendermos mais profunda e eficazmente a enorme variedade de imagens com que os dispositivos tecnológicos nos vêm cada vez mais capacitando e transformando a nossa sensibilidade e percepção. Neste artigo serão dados e discutidos vários tipos de invenção artística e poética que poderão ser considerados como exemplos dessa complexidade a que agora já não poderemos escapar, tentando avaliar também as suas conseqüências e as perspectivas futuras.

Palavras-chave: mente, arte, rede, nuvem, ciborgue, múltiplo, complexo, performance, live-cinema, fim, futuro. 
A mente inventa o pensamento.

A rede difunde a informação.

As artes o que farão?

A nuvem absorve pensamento, arte e informação, transformando-os em qualquer coisa que não sabemos ainda o que é, mas não é de ninguém.

A invenção é o processo pelo qual a materialidade orgânica do cérebro, através de impulsos eletroquímicos, se desmaterializa e ganha significado.

A informação resulta da possibilidade de comunicar esse significado a outros alguéns que não nós próprios, de preferência com um mínimo de distorção, constituindo-se em redes e estas em nuvens.

A totalidade de todas as informações transmitidas em todas as direções, em todas as redes e em todos os momentos, passados, presentes e futuros, por meios electrônicos desmaterializados, constituiu-se numa nuvem plural que provavelmente não tem começo nem fim, mas que existe e é "acessável" por qualquer ser humano devidamente equipado ciberneticamente e por isso transformado em ciborg.

Todas as pessoas que se sentam diante de uma tela de computador, utilizam a Internet e os seus "lugares" de conversa, que usam um telefone celular, um $i P a d$, ou o Skype, libertam-se das limitações geográficas e temporais e a sua percepção é transformada na de um ciborg. Cito resumidamente a opinião de Amber Case, jovem americana, antropóloga do ciberespaço.

\section{E a arte, AS ARTES?}

Parece óbvio dizer que não existe uma só maneira de encarar a complexidade e de com ela trabalhar inventivamente. Porque se só houvesse uma, não existiria complexidade. E o nosso "agora" é complexo. Dizer isto tem o sabor de uma tautologia ou de uma verdade que ninguém se lembraria já de contestar.

Mas, no entanto, falar numa estética da complexidade parece-nos talvez problemático... embora as orquestras sinfônicas que podem chegar a ter mais de cem instrumentos musicais tocando simultaneamente uma sinfonia de Beethoven ou de Mahler, não nos causem qualquer estranheza. 
E uma autopista com 4 ou 5 faixas de rodagem em cada sentido, repleta de automóveis em movimento, é uma situação banal do quotidiano, que faria exultar de satisfação e de incredibilidade, um qualquer artista futurista de há cem anos atrás... Para nós tal situação é apenas mais uma forma de constrangimento e um sinal do perigo que a toda hora nos espreita nas grandes metrópoles. Mas se fotografarmos ou filmarmos essas autopistas, de dia ou de noite, de um avião ou helicóptero, teremos belíssimas imagens da complexidade móvel. Imagens, isto é, sinais esteticamente ativos e prazerosos, das estruturas complexas em que vivemos. Tais imagens que são naturalmente ícones, têm também a capacidade de agir sobre os nossos sentidos como índices sensíveis de fruição, tal como agem sobre nós as chamadas "obras de arte"! E essas imagens têm tais capacidades (ditas estéticas), justamente porque foram obtidas através de dispositivos tecnológicos comandados por homens que tinham uma intenção: obter imagens capazes de nos impressionar e provocar prazer, tal como todos os artistas sempre tiveram, com os instrumentos e as tecnologias do seu tempo, desde a pré-história até hoje! Só que hoje a situação é sinestésica e por isso complexa, podendo ser global e instantaneamente difundida! John Cage disse (numa entrevista dada, tendo um gato na mão, numa janela aberta sobre as ruas de New York por onde entravam todos os ruídos do tráfego intenso) que para ele essa paisagem visual-sonora bastava como fato sensorial sinestésico e que certamente o gato sabia tudo sobre isso!... (citação feita de cor).

Por isso uma estética da complexidade é não só possível, como necessária para entendermos mais profunda e eficazmente a enorme variedade de imagens com que os dispositivos tecnológicos nos vêm cada vez mais capacitando e transformando a nossa sensibilidade e percepção. E não é preciso abdicarmos de todo o conhecimento filosófico e teórico do passado, mas sim de o reprocessarmos numa perspectiva múltipla e probabilística, observando fenomenologicamente com olhos-outros, tanto o que vemos e sentimos, como o que nos é feito ver e sentir pelos equipamentos produtores de imagens de que dispomos e cada vez mais nos seduzem e utilizamos. Isto porque as imagens-outras que hoje produzimos, são outras e diferentes, mas são imagens, cada vez mais outras-diferentes e autônomas, cada vez mais capazes de nos surpreender, obrigando-nos a persegui-las e a questionarmo-nos sobre as nossas próprias capacidades de invenção, lançando-nos

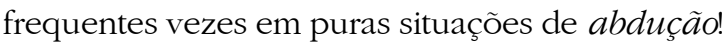

Quando o vídeo analógico aparece, ao alcance de todos, durante os anos 60 do século XX, como um novo suporte, mas também como um novo meio de gerar imagens complexas, ele apela imediatamente para a possibilidade de um 

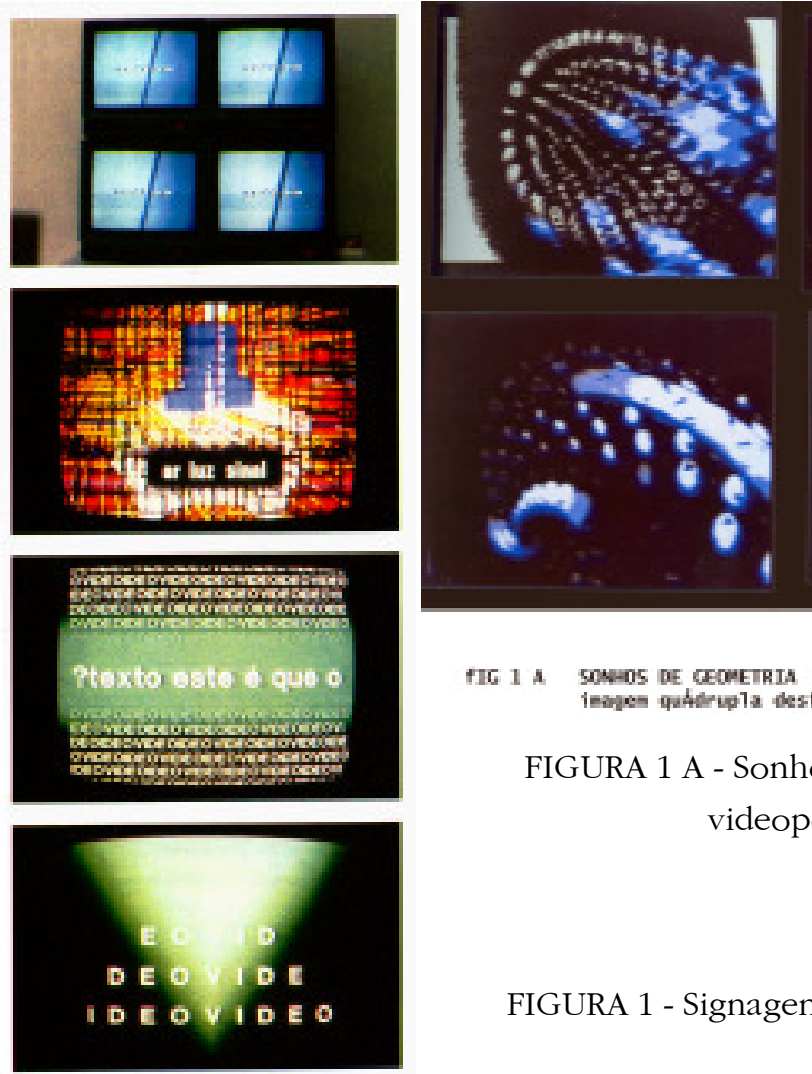

FIC 1 A SONEOS DE CEORETRIA VIDEOPOEN ieaven quadrupla desfasada M.C. 1993

FIGURA 1 A - Sonhos de Geometria / videopoema

FIGURA 1 - Signagens / videopoesia

fig't videograsas de

diferente tipo de invenção poética, explorando as suas potencialidades de movimento, cor e transformação, mas também de edição não sequencial. É o nascimento da videopoesia que logo, nos anos 80 , se complexifica com o vídeo digital e amplifica com a possibilidade das imagens múltiplas. Muitas das apresentações internacionais da minha videopoesia, das séries Signagens (1980-89) [FIG. 1] e Sonhos de geometria (1993) [FIG. 1A] foram feitas usando baterias de vários monitores de TV, com imagens simultâneas ou defasadas de 2 ou 3 segundos, para aumentar a complexidade e enriquecer a percepção visual dos espectadores-fruidores.

Na exposição, O caminho do leve, realizada em 2006, no Museu de Arte Contemporânea da Fundação de Serralves, na cidade do Porto, em Portugal, apresentei, além das referidas séries de videopoemas, a nova série denominada Fractopoemas (2004-05), em imagem múltipla, com baterias de 4 monitores de 


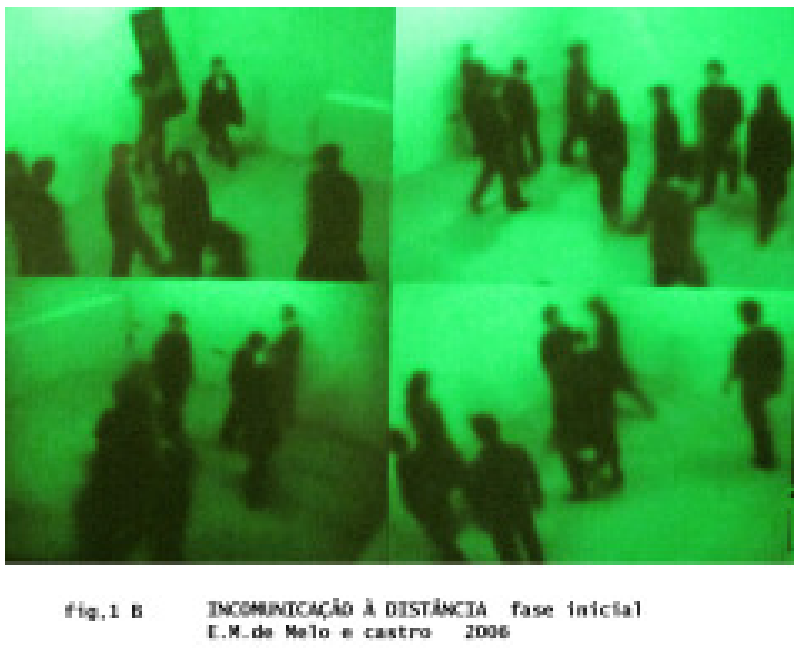

FIGURA 1 B -Incomunicação à distância / performance

grande formato, em salas próprias, denominadas Cavernas Cibernéticas, enquanto no exterior dessas Cavernas os mesmos videopoemas eram projetados com grande ampliação, nas paredes e no teto da sala comum, deslocando-se lenta e aleatoriamente, nunca percorrendo o mesmo caminho.

Também durante a inauguração dessa exposição, realizei uma performance denominada Incomunicação-à-distância [FIG.1B]. Numa sala quadrada completamente fechada, 25 pessoas munidas de telefones celulares, deslocam-se aleatoriamente, sem se tocarem, tentando continuamente estabelecer contacto com o exterior, sem no entanto, o conseguirem. Ao fim de cerca de 20 minutos começam a cair uma a uma, desistindo da comunicação e talvez morrendo... Toda a performance foi registrada simultaneamente por 4 câmaras de vídeo colocadas nos vértices da sala quadrada (assim se obtendo 4 perspectivas diferentes) e conectadas a 8 monitores colocados no exterior da sala, dispostos numa ordem não sequencial (13243142, por exemplo). Assim os espectadores assistiam à movimentação desencontrada de 200 pessoas virtuais tentando comunicar, não se sabe com quem. O som era captado também por vários microfones dentro da sala e mixado para o exterior, constituindo um poema sonoro simultâneo. Desta performance realizaram-se registros vídeo que foram editados posteriormente numa só imagem dividida em 4 partes, assim se obtendo uma imagem múltipla que apresenta apenas a movimentação de 100 pessoas virtuais, numa só tela de TV. Essa edição integra o DVD interativo denominado ANTSINC - antologia sincrônica, que faz parte do meu livro de ensaios, Livro de releituras e poiética contemporânea. 
É numa encruzilhada sensorial, cheia de armadilhas, e por isso amplamente sedutora, que as performances multimédia que Márcio André (Rio de Janeiro) tem recentemente realizado, vêm ao nosso encontro simultaneamente como produtos estéticos complexos e intuições poéticas inusitadas, dando-nos a partir de elementos díspares, muitas vezes do nosso contemporâneo dia a dia, vídeos captados no YouTube ou realizados para outros fins. Esses elementos visuais são aleatória ou programadamente sobrepostos e sintetizados, num clima pansinestésico totalizante, não se sabe bem de quê... É esse o encanto e o novo que essas performances nos oferecem pelo tratamento das imagens múltiplas e das sonoridades casuais eletronicamente tratadas mas não sincronizadas e pela presença surpreendente de um autor-executante de violino eletrônico, assim como de atores ou bailarinos que são sombras fantasmáticas de uma talvez já desnecessária presença humana. [FIG. 2]

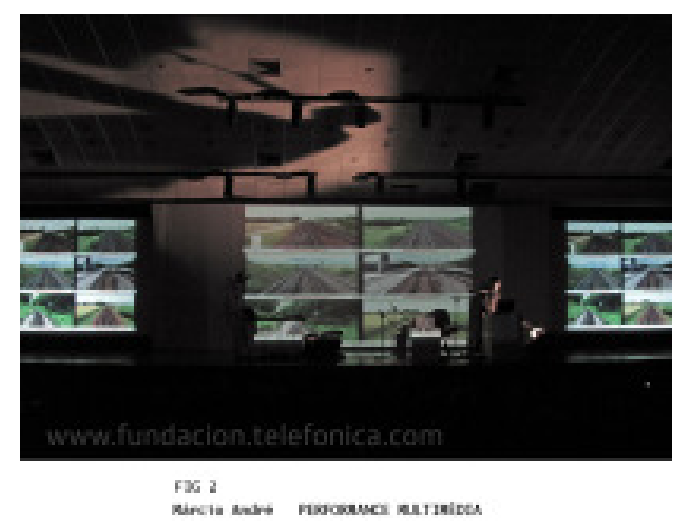

FIGURA 2 - Márcio André / performance multimídia

Todos estes ingredientes simultâneos levam-nos ao mundo das novas propostas do chamado Live Cinema, ou cinema interativo. [FIG. 3]

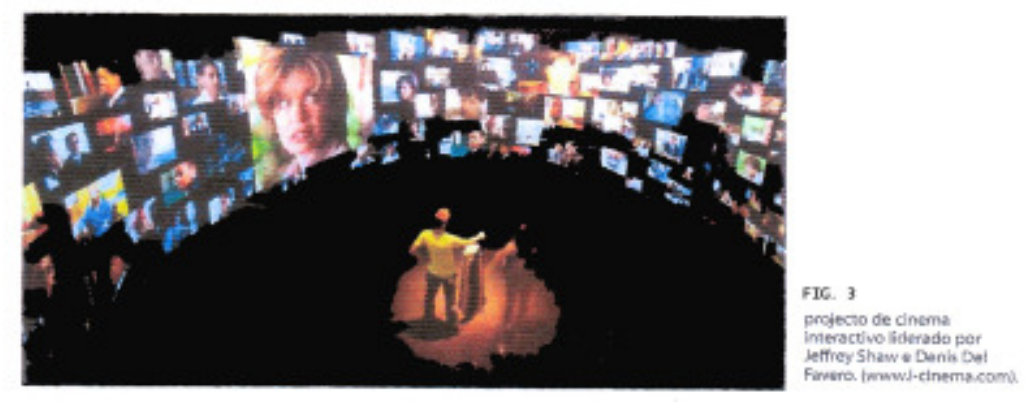

FIGURA 3 - Live Cinema 
"Cinema is dead. Long live cinema." A frase é do cineasta e artista plástico britânico Peter Greenaway, que afirma que o cinema em sua especificidade, que nasceu com Eisenstein, consolidou-se com Fellini e rompeu barreiras com Godard, está morto e urge a necessidade de reinventá-lo para se adequar às características contemporâneas. Greenaway afirma que o cinema morreu em 31 de setembro de 1983 quando o zapping e o controlo remoto foram introduzidos às salas do mundo.

Este é o parágrafo de introdução do capítulo dedicado ao Live Cinema, da Dissertação de Mestrado que o meu ex-aluno e orientando João Beira apresentou e defendeu em 2009, na Faculdade de Belas Artes da Universidade do Porto, em Portugal, intitulada "A performance audiovisual: do Digital Jockey ao Live Cinema".

Sendo ele próprio um digital jockey e vídeo jockey profissional, a sua dissertação e defesa foram recebidas pela Universidade com muito agrado e até curiosidade, obtendo a classificação mais alta. Se aqui refiro estes fatos é porque considero que a pesquisa e o desenvolvimento dado, particularmente à nova noção de Live Cinema, tem tudo a ver com o assunto deste artigo, sendo matéria ainda quase inédita.

Mas afinal em que consiste o Live Cinema?

Será melhor não tentarmos uma definição, porque isso seria certamente restritivo e o Live Cinema é um produto estético aberto, imprevisível e irrepetível. Por isso mesmo é Live, não obedecendo a roteiros nem guiões de sequências perprogramadas. Mas é o resultado da interação de máquinas cibernéticas e homens (já ciborgues?), executando planos de sequências não sequenciais que resultam em edições caóticas, teoricamente sem princípio nem fim, de imagens visuais-sonoras não convergentes, num espaço de simbiose físico-virtual.

Assim os fatores a ter em conta numa realização Live Cinema são estratégias de:

1) Espaço físico

2) Espaço virtual

3) Interatividade

Quanto ao espaço físico, João Beira chama atenção para o fato de que a postura física dos agentes no Live Cinema não é semelhante à dos projecionistas do cinema convencional que dirigem a performance fora do campo de visão dos espectadores. Eles têm uma presença em palco tal como os digital jockeys, pois são protagonistas da componente laboritorial associada à performance. 
Assim o processo de edição e composição é objeto e elemento integrante do processo artístico e como tal deve ser observado, analisado e fruído. "O design do espaço funciona como uma metáfora dos principais temas da cultura dos computadores: interatividade, falta de hierarquia e modularidade", segundo Manovich (2001).

O espaço virtual é definido pelo seu elemento principal: os softwares usados. O design desta interface deve ser construído de uma forma que permita a manipulação rápida e intuitiva, com destaque para um visionamento constante dos parâmetros mais importantes, sendo os softwares de estrutura aberta os mais interessantes. O processo deve poder ser controlado por um sistema de feedback entre o processamento de imagem, o performer, e o som. Esta ferramenta, que pode ser concebida especialmente, não deve ser limitada a uma única composição pois deve funcionar como um instrumento musical...

A interatividade aparece como uma das naturais e mais problemáticas questões a levantar a propósito do objeto artístico quando integrado no ambiente daquilo a que se chamou "novas tecnologias". Ao longo dos anos 90, a função cultural do computador foi mudando. Antes era uma ferramenta, agora é um meio e um veículo de troca de informações. Com o computador estamos interagindo com uma máquina, mas também com formas culturais codificadas digitalmente. Tais interfaces consistem basicamente em metáforas utilizadas para organizar e contextualizar os dados no computador, seja na forma de ícones, hipertexto, metonímias, ou outras formas de associação. A fusão do espaço virtual com o espaço físico passa pela adoção de tecnologias que permitam realizar essa passagem de forma rápida, prática e intuitiva, através de processos interativos. O desenvolvimento das interfaces deverá levar em conta o poder da linguagem, incluindo aí as conexões poéticas, valores culturais e a subjetividade.

Com o Live Cinema estamos em plena complexidade inventiva e estética, tanto do lado dos agentes interventores como dos espectadores fruidores. A fusão homem+máquina está num ponto crítico de quase materialização... virtual [FIG. 4]. 

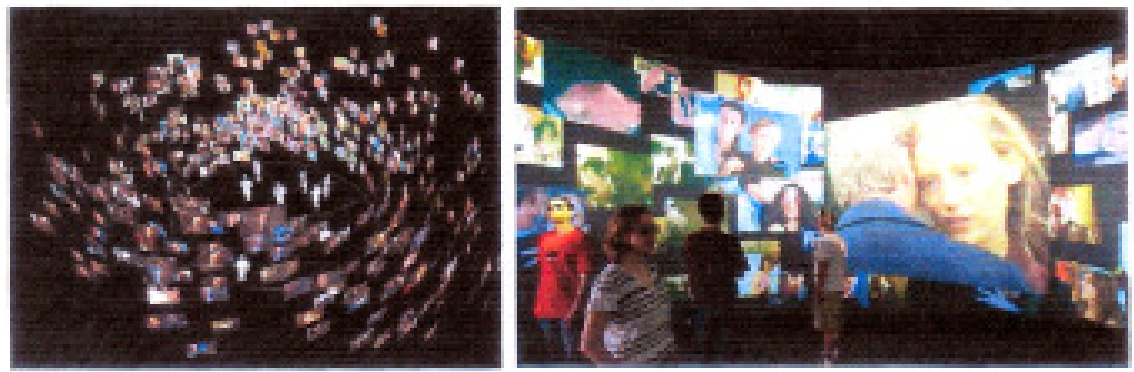

IIG 4

O processo de apresentaçoo visual nbo passa actualmente speras pela utleaTipes calo de projectores, e a ud lasçbo de sistemas de leds, ou monitoves lods e plasmas de Live Cines: em excalas mais pequenas, represertarn ahernothas de suporte. Também a utiliza-

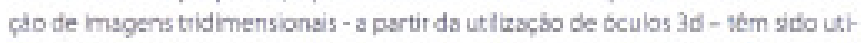
leadas em cinemas do circulto comercial, e representam uma therica sensarial

FIGURA 4 - Tipos de Live Cinema

\section{Arte e máquinas não é o mesmo que artimanhas...}

Está sendo rápido, muito rápido! Tudo está sendo rápido demais!

De repente os primeiros dez anos do século XXI passaram mais rapidamente que os últimos dez anos do século XX! Como? Por quê?

Possivelmente porque o século XX já estava cansado... Porque nós já estávamos cansados de toda a crueldade do século XX, esperando pelo ano 2000 para tudo mudar. E, como nada mudou, subitamente, de um dia para o outro, tudo começou a ser mais rápido para nos compensar da desilusão que começou no século XXI e se prolonga dia a dia, ano a ano... Até quando? Até que tudo começa a acontecer ao mesmo tempo, roubando-nos a ilusão do próprio tempo que importamos do século XX já fragmentada e gasta. Por isso o tempo agora já não dá para gastar, mas desgasta-nos, deixando-nos fora de tempo, correndo atrás dos nossos fantasmas, projetos, desejos, saberes e ignorâncias, como afinal sempre aconteceu, mas não queríamos acreditar. Agora dizer que "nada se sabe" equivale a dizer que nada ignoramos, o que obviamente é mentira em ambos os casos, mas é a verdade que nos fazem acreditar rapidamente impelindo-nos em todos os sentidos, acelerados ao mesmo tempo, que não é tempo nem tempos. É uma outra categoria metafísica, sem nome ainda mas a que se vai chamando, à falta de melhor, de contemporânea, ou melhor, de agoridade...

Somos então contemporâneos daquilo que rapidamente acontece e não temos tempo de chegar a conhecer... porque perdemos o tempo a tentar conhecer o que não tínhamos, nem nunca tivemos: o Tempo! 
Então, rapidamente, voltamo-nos para o espaço, na esperança de encontrarmos o que tão rapidamente tínhamos perdido. Mas a ciência logo nos adverte que tempo e espaço são a mesma coisa, embora com sabores diferentes, dirá o poeta...

É pois, no espaço que essa agoridade rápida nos envolve. Agora dizer "rápido" é uma forma já desajustada de dizer em expansão ou em contração, sem sabermos muito bem que referências físicas usar para sabermos onde estamos. O que afinal talvez não seja tão grave ou importante como a nossa precária percepção possa julgar... tão dominada está por sentidos já desajustados às dimensões circunstanciais da nossa vida, tanto quanto à falta dessas dimensões.

Agora, já não é uma expressão do tempo, mas do espaço, que nos poderá interessar, querendo referir onde pensamos que nos encontramos e quais as coordenadas que podemos julgar ter para saber que estamos onde estamos. É que estamos no agora! E esse agora pode ser sempre diferente, mas diferente também não sabemos de quê ou em relação a quê. Só sabemos que o agora é relativo. Cada vez que o considerarmos como absoluto, ele altera-se, e continua a ser agora.

Estas considerações, que nada têm de "futuristas", como se diria há cem anos, só agora são possíveis para nos referirmos às condições em que a nossa função inventiva se encontra quando contemplamos o que foi feito nos últimos anos do século XX, com as possibilidades abertas pelas tecnologias, então em rápido desenvolvimento, quando usadas poiéticamente para produzir objetos, então ditos de arte.

Então era possível pensar e dizer:

Uma nova espécie de artistas está a surgir! Um novo tipo de arte será feita por esses novos artistas, agora equipados e turbinados com novos equipamentos e instrumentos tecnológicos!

Mas aconteceu o que não soubemos prever: que o uso intensivo das novas máquinas tecnológicas trazia consigo, a par de uma recuperação dos velhos conceitos de poiesis, tecné e agora, que nos iriam proporcionar um novo tempo de invenção. Em vez disso, trouxeram uma nova era de barbárie dita falsamente de artística e comunicativa, explorando apenas a parafernália tecnológica para produzir ruídos na esfera do tempo acelerado que se esvai em cada momento, num mundo temporal que no AGORA já não existe. 
Teremos então de considerar que hoje, na segunda década do século XXI, onde tudo se passa já no espaço, essas ditas maravilhosas novas tecnologias são desenvolvidas e usadas visando um mercado ultrapassado, temporalmente definido, visando a manutenção de um mundo que pertence ao passado, retrógrado e culturalmente barbárico. É esse aspecto histérico, ruidoso e nem sequer superficial que as televisões de todo o mundo mantêm, a internet se expande e as grandes companhias promovem, oferecendo falsos novos produtos, como os telefones celulares, que fazem tudo, e toda a sorte de iPads, iPeds, iPids, iPods e iPuds (?!) ou outros que apenas visam a obtenção de lucros milionários, prosseguindo cegamente na manutenção de um mundo velho, que visivelmente se despedaça, e cujos símbolos estão gastos ou podres.

Mas nós sabemos que quando os valores simbólicos de uma civilização se aviltam, desgastam ou entram em declínio, como é nitidamente a situação contemporânea, o caminho está aberto para a invenção de novos símbolos, tarefa que pertence aos poetas e à poesia, desde as mais antigas civilizações. Historicamente pode mesmo traçar-se um eixo com o aparecimento de poesias visuais, periodicamente, sempre que uma cultura decai e outra vai surgindo.

É como diz Franz Mon (poeta concreto Checo): "A linguagem espacialmente articulada rompe com qualquer linguagem convencional aprovada pela sociedade que chegue aos seus limites ou que, por qualquer outra razão, não possa mais ser utilizada."

Esta situação leva a constatar que o século XXI ainda não começou, pois raros apenas estão conscientes das enormes potencialidades inventivas que jazem nas mãos de raros verdadeiros artistas da nova era espacial do AGORA. Artistas estes tecnologicamente equipados e aptos para desvendar os novos espaços simbólicos.

Mas o que poderá ser AGORA?

Agora é a descoberta sistemática de novos planetas no espaço transgalático? Agora é a obstinada procura científica da partícula de Deus, sem nada se encontrar?

Agora é a percepção sinestésica de que todos os sentidos são equivalentes, todas direções são as mesmas direções, tudo o que sabemos hoje é tão importante como o que sabiam os nossos antepassados e o que saberão os nossos sucessores... Que todos morreremos em vão como todos sempre morremos... ou talvez não, desde antes do começo do tempo. Tempo que agora é ESPAÇO? Agora será tudo e em toda a parte? 
Agora será a abolição do princípio tanto como do fim?

Agora será uma nuvem onde tudo se passará, mas onde não se perguntará por um novo tipo de artista, mas sim por um novo tipo de homem que está a nascer, talvez sob a forma de um ciborg?

\section{O homem, MAS QUE HOMEM?}

Diretamente da Internet recolho a seguinte informação, que reelaboro criticamente:

\section{Tecnologia singular}

Ainda não existe consenso sobre quais seriam os agentes responsáveis pela chamada "singularidade tecnológica", fenômeno que poderá começar a ocorrer cerca do ano $2045 \ldots$

Há quem acredite que ele decorrerá naturalmente, como consequência dos acelerados avanços científicos em diversas áreas como informática, inteligência artificial, astrofísica, medicina, nanotecnologia, engenharia genética, robótica, ciências da cognição... Outros acreditam que o surgimento iminente de supercomputadores dotados da chamada superinteligência, resultante do contínuo aumento da velocidade de processamento dos computadores, sem aumento dos custos, será a base de tais avanços. Outros argumentam que somente com uma inteligência superior à humana poderíamos ter avanços científicos e tecnológicos tão rápidos e importantes, baseando-se talvez no famoso teorema de Godel. Há também quem acredite na integração homem-computador para o surgimento da superinteligência, mas a tecnologia necessária para tal pode estar mais distante de ser alcançada do que a inteligência artificial.

Vários cientistas, entre eles Vernor Vinge e Raymond Kurzweil, e também alguns filósofos, afirmam que a "singularidade tecnológica" é um evento histórico de importância semelhante ao aparecimento da inteligência humana na Terra, ou simplesmente que a "singularidade tecnológica" é, na verdade, a quarta revolução industrial, e nada mais. Nada tendo a ver com o mito do "fim do mundo" e muito menos com o fim da humanidade tal qual a conhecemos. Poder-se-á até perguntar a propósito, quais são as diferenças entre nós próprios, homens resultantes da terceira revolução industrial, e os que nos antecederam na segunda revolução 
industrial. Chegaríamos à conclusão que essas diferenças são predominantemente culturais e que a evolução da espécie necessitaria de muito mais tempo, para que o aparecimento e triunfo dos ciborgs orgânico-materiais seja realmente possível. Isto mesmo tendo em conta a extraordinária aceleração dos processos evolutivos de que vimos falando e que são incontestáveis, mas não ainda suficientes...

Há muito tempo que o cinema e a ficção-científica abordam temas relacionados ao fim do mundo, mas a "singularidade tecnológica" como ameaça global, é algo bem mais recente. Um exemplo disso é o filme Matrix, lançado em 1999, que apresenta uma versão bastante elaborada de como poderá ocorrer a "singularidade tecnológica". No filme, uma guerra entre homens e máquinas inteligentes é travada entre 2094 e 2102 com a derrota e consequente escravização da humanidade. De forma semelhante, o filme O exterminador do futuro 3: a rebelião das máquinas aborda uma longa e inacabada guerra entre homens e máquinas.

Por outro lado, alguns filmes, como, por exemplo, Eu, robô do escritor Isaac Asimov, são mais cautelosos e abordam uma vitória humana. Outros, como $O$ homem bicentenário, também de Isaac Asimov, mostram que a inteligência artificial pode ser totalmente benéfica e que a "singularidade tecnológica" pode não trazer perigos potenciais à humanidade. Mas também as obras ficcionais de Carl Sagan vão no sentido de uma supra-humanidade já existente algures no universo...

A "singularidade tecnológica" de que se começa a falar, será portanto um conceito hipotético resultante do hibridismo entre homens e máquinas, ou seja, do advento dos ciborgs substitutos dos homens, mas, no entanto, resultantes da atividade inventiva do próprio homem.

\section{Tópicos para um NÃO FIM}

À "singularidade tecnológica" são atribuídas muitas propriedades extra-humanas para além de uma superinteligência que ainda não se sabe muito bem no que consistirá, assim como superresistência às piores doenças que hoje nos afligem, e um aumento incomensurável da duração da vida, conduzindo talvez ao fim da morte, ou seja, à imortalidade.

Se a revolução agora apelidada de "Tecnologia singular" chegar a ser uma realidade híbrida entre o atual e o virtual, todo o sistema mental e sensorial como até agora o conhecemos, será alterado. E assim todo o sistema das artes, fato 
que já se pode começar a observar nas artes produzidas em computador, através da crescente complexidade das imagens e dos sons múltiplos, marcando indelevelmente essas invenções artísticas com a marca da "tecnopeia" que é a marca psico-estética que essas ciberobras deixam na mente humana.

A já citada ciberantropóloga Amber Case acredita que o processo já começou e que, portanto, este texto que agora escrevo no computador é o resultado da subliminar fusão homem-máquina que eu já sou e que os leitores que eventualmente lerem este texto são igualmente ciborgs involuntários, porque a energia comunicativa contida neste texto já não é exclusivamente humana...

Mas, atenção! Isto já não é ficção científica, como nós ainda a conhecemos desde Júlio Verne até Isaac Asimov, Stanislav Lem, Ray Bradbury e outros autores, que ainda cultuamos. Nem sequer os filmes que atrás citamos terão muito a ver com o significado deste novo conceito. Tal como as utopias do século XX: 1984 de George Orwell ou Admirável mundo novo e A ilha, ambos de Aldous Huxley. Antes, se chegar a existir, esse conceito será o começo de uma invasão que virá ou não de dentro de nós próprios, homens que aceitaram e aceitam o universo neotecnológico em que todos afinal vivemos e do qual usufruímos, quase sempre ingenuamente.

Um aviso contra essa ingenuidade poderá ser o filme Fabrenheit 451, realizado por François Truffaut em 1966, a partir de um romance de Ray Bradbury, sendo uma metáfora poética sobre a resistência à destruição dos valores humanos constituídos pela escrita e a leitura, mas também pela conservação da memória dos homens. Penso que é urgente voltar a ver e a discutir este filme!...

Que uma das funções até agora ditas positivas das novas tecnologias seja a realização dos sonhos e ideais mais remotos da humanidade, parece-nos agora começar a ter um preço demasiado alto, pois implicaria o fim do Homo Sapiens Sapiens para passarmos a ser um outro Homo-?... no qual por enquanto ainda não nos reconheceremos, embora com características que secretamente ou não secretamente, aspiramos possuir.

Ainda há poucos anos se podia escrever o seguinte ( que eu escrevi...) num ensaio intitulado, já sintomaticamente, Notas humanas sobre Inteligência Artificial ou máquinas de dar respostas, texto colocado no fim do já referido Livro de releituras e poiética contemporânea.

No triângulo "operador humano+hardware+software" as opções do operador humano são realizadas de um modo superlativo, mas essas opções são limitadas pelos elementos-máquina. A razão judicativa pertence ao elemento humano. Mas, até quando? O X da questão da IA está precisamente aí. No entanto, 
será possível replicar as funções orgânicas do cérebro e da sua mente, com elementos, componentes e processos não orgânicos? Este é o desafio, esta é a dúvida.

Mas desta dúvida pode surgir uma bifurcação, e nós sabemos que as bifurcações comportam sempre um aumento da complexidade e a passagem para uma outra dimensão.

Dessa bifurcação poderá surgir, inicialmente, a configuração de dois caminhos para a Inteligência Artificial:

1) O prosseguimento da simulação da inteligência humana

2) O desenvolvimento de uma inteligência-máquina totalmente nova e diferente da humana, em meios, processos e objetivos.

Será na integração complexa destas duas inteligências que o futuro se jogará? (Esta será por agora, mais uma pergunta sem resposta.)

[...] A simulação do cérebro humano terá portanto os seus limites, tal como a construção de outros sistemas lógicos diferentes do pensamento humano. Só provavelmente serão viáveis com o recurso ao pensamento humano e, por isso, ao cérebro do homem, tal como ele é ou será.

No entanto chegam rumores de que a já velha idéia da expansão e melhoramento da performance do cérebro humano está ganhando novas probabilidades. Não mais através do uso de químicos psicodélicos ou outros [...] mas sim pelo implante no cérebro humano de micro ou manoships que melhorariam e transformariam o seu funcionamento, dotando o homem com capacidades de percepção, processamento, comunicação, capacidade de decisão e invenção, por enquanto nem sequer imagináveis. É claro que resultariam ciborgues super humanos, dotados também de extraordinária força física e imunes, talvez, a certas doenças cerebrais e ao envelhecimento.

A questões como estas a "Tecnologia singular" pretende vir adiantar uma resposta, a meu ver ainda ficcional, não já ao modo espetacular da ficção científica, mas de uma ficção conceptualizada que talvez substitua também a invenção artística, como a temos conhecido, por algo muito provavelmente coerente com a presente aceleração e transformação da percepção do tempo, do espaço e do modo de viver dos humanos, no agora precário que vivemos. Mas será essa transformação efetivamente desejável, ou só provável, podendo de fato nem chegar a acontecer? Dependerá de quê ou de quem? 
Certamente/talvez de nós próprios, HOMENS... Mas é perante a perplexidade embutida nestas perguntas que ressurge a ideia de fim que, ligada a uma ideia contida no prefixo "pós", teve grande voga na segunda metade do século XX, principalmente no caso do pós-moderno. Nessa época fértil em equívocos, considerou-se principalmente o fim da história, e de um modo geral o fim de tudo, quando afinal aconteceu apenas o fim de nada. Isto é, nada teve fim, mas começaram as transformações trazidas pelo rápido avanço das ciências e das tecnologias e sua repercussão na vida diária e na problemática neoexistencial de todos nós.

Também a ideia de fim do mundo, que tivera grande voga na passagem do primeiro para o segundo milênio, repercutiu na recente passagem do segundo para o terceiro milênio. Mas pode dizer-se que nunca desapareceu do subconsciente mais remoto no mundo ocidental, principalmente ressurgindo logo após a segunda guerra mundial, em 1945. Lembro-me muito bem de um boato ter aparecido em Lisboa, de que o mundo iria acabar em breve como resultado das explosões atômicas. Então, eu até escrevi um conto-poema em prosa, com o título "Só eu sei" que publiquei no meu primeiro livro Sismo, em 1952 e hoje se encontra na Antologia efêmera. Esse texto foca o aparecimento e expansão do boato do fim do mundo num determinado dia, até a chegada desse dia, em que realmente nada aconteceu. Perante tal verificação, concluí que só eu sabia que o mundo tinha acabado...

Este salto subjetivo creio que poderá ter hoje um valor bem atual... quando circula a profecia de que o mundo vai acabar em 2012, baseada no fato de o calendário Maia terminar aproximadamente nesse ano, o que seria o fim do tempo. Esta ideia é desenvolvida em vários livros, alimentando crenças religiosas, e dispõe de dezenas de entradas na Internet. Basta pesquisar em "ano 2012".

Também a "Tecnologia singular", que prevê para 2045, ou mais cautelosamente, para os anos de 2025 a 2070, o fim da espécie humana como a conhecemos, se arrisca a ser considerada como mais um boato, ou crença de tipo religioso, mas desta vez cuidadosamente estudado e até "cientificamente" ancorado em fatos existenciais e culturais da nossa contemporaneidade. Por isso merece ser considerado como algo que de algum modo nos diz respeito, venha a acontecer nas datas indicadas ou mesmo a não acontecer. Porque no horizonte do nosso futuro de invenção e criação estão já entre nós os primeiros sinais dos ciborgs, como a jovem antropóloga Amber Case nos adverte, porque nós próprios "não somos como o Robocop ou o extreminador do futuro, mas somos ciborgues toda a vez que olhamos para uma tela de computador ou quando olhamos os dispositivos dos nossos celulares" tal como ela disse em recente entrevista à Folha de São Paulo, publicada em 9 de março de 2011. 
Para terminar este artigo não posso deixar de pensar que agora o nosso destino tenderá a não estar na mão de políticos, economistas ou historiadores e mesmo nem na mão dos apenas cientistas, mas sim e muito mais, nas mãos dos artistas e dos poetas que souberem dar um uso novo e inventivo aos extraordinários meios tecnológicos de que dispomos já e que cada vez mais estarão ao nosso alcance para que, fundindo ciência e poesia, os futuros ciborgues possam vir a ser mais humanos do que nós próprios hoje somos. Instituindo PAZ, DIÁLOGO, SAÚDE, LONGIVIDADE, INVENÇÃO, FRUIÇÃO ESTÉTICA, INTELIGÊNCIA como características básicas dessa talvez humanidade híbrida, agora já inevitavelmente complexa.

Sem nos esquecermos da advertência que já nos passados anos cinquenta do século XX, fez o grande crítico inglês Herbret Read: "quanto mais longe estamos de uma civilização, mais ela será representada e avaliada pelas obras que os seus artistas e pensadores nos deixaram”.

Cito de cor, mas sei que assim será.

Minds - Arts - Nets - Clouds

Abstract: Mind invents thought. Net expands information. Arts wath will they do? The cloud absorbs thougt, art and information transforming them in a kind of a thing that we do not know wath it is, but doesn't belong do anyone. The totality of all the informations brodcast in all directions, in all nets and in every moment past, presente and future by dematerialized electronic media, makes itself into a plural cloud probably with no bebinning and no end, but certanly actual and possible to be acessed by any human being, dully and cybertitically equiped, thus becamming a cyborg. This way, our "now" is a complex one, and an aesthetics of complexity is, not only possible, but necessary for us to understand more profoundly and with more efficacy the great variety of images made possible by the thechnological devices that presently exist and thus transforming our sensibility and perception. This article presents and discusses various types of artistic and poetic invention that can be considered as examples of that complexity from witcht we can't escape and also trying to evaluate their consequences and future perspectives.

Keywords: mind, art, net, cloud, cyborg, multiple, complex, performance, live-cinema, end, future. 


\section{Referências}

2045: A imortalidade do homem. Disponível em: <http://www.entranet.com.br/ noticial/item/4hO/2045-a-imortalidade-do-homem.html/>. Acesso em: 21 nov. 2011.

BEIRA, João. A performance audiovisual: do Visual Jockey ao Live Cinema. 2008. Dissertação (Mestrado) - Faculdade de Belas Artes, Universidade do Porto, Porto, 2008.

CASE, Amber. Amber Case. Folha.com, 2011. Disponível em: <http:// www1.folha.uol.com.br/tec/886162-leia-entrevista-com-a-antropologa-ciborgueamber-case.shtn/>. Acesso em: 21 nov. 2011.

GROSSMAN, Lev. 2045: The Year Man Becames Immortal. Time: Magazine Science. Disponível em: <http://www.time.com/time/magazine/article/0,9171,2048299,00. html>. Acesso em: 21 nov. 2011.

MELO E CASTRO, E. M. de. Livro de releituras e poiética contemporânea. Belo Horizonte: Veredas \& Cenários, 2008.

MELO E CASTRO, E. M. de. O caminho do leve. Porto: 2006. 303 p. Catálogo de exposição, 11 fev. - 30 abr. 2006, Museu de Serralves.

MUNIZ, Diógenes. Feira de tecnologia destaca trabalho e vida na "nuvem". Folha de São Paulo, São Paulo, 9 mar. 2011. Tec, p. 3.

SCHWARTSMAN, Hélio. Análise: somos ciborgues há dezenas de milhares de anos. Folha.com, 2011. Disponível em: <http://www1.folha.uol.com.br/tec/885176-analisesomos-ciborgues-ha-dezenas-de-milhares-de-anos.shtm/>. Acesso em: 21 nov. 2011. 